\title{
Effects of Delayed Payment of Contractors on the Completion of Infrastructural Projects: A Case of Sondu-Miriu Hydropower Project, Kisumu County, Kenya*
}

\author{
Maurice Paul Okeyo, Charles Mallans Rambo, Paul Amollo Odundo \\ University of Nairobi, Nairobi, Kenya
}

\begin{abstract}
Sondu-Miriu hydropower (SMHP) project experienced delay for about five years and one of the contributing factors was delayed payment of the contractor, with ripples effect extending down the contractual hierarchy. This study assessed the effects of delayed payment of the contractor on the completion of SMHP project in Kisumu County, Kenya. More specifically, the study addressed two research questions: What is the relative importance of delayed payment of the contractor compared to other forms of contractual delays? What is the perceived effect of delayed payment of the contractor on the project's completion? A causal-comparative design was adopted and primary data sourced in May 2011 from 39 senior management staff of contractual parties. Relative importance index (RII) was used to determine the relative importance of perceived effects of delayed payment of the contractor on the project's completion; while Kendell's coefficient of concordance was applied to determine the degree of agreement among participants regarding their perceived effects of delayed payment. The study found that delayed payment of the contractor affected the project by causing: loss of productivity and efficiency $(71.8 \%)$; increase in time-related costs (71.8\%); re-scheduling and re-sequencing of works (69.2\%); extension of time and acceleration (69.2\%); as well as prevention of early completion (53.8\%). The study concludes that timely payment of contractors is crucial for ensuring the continuity of works and completion of infrastructural projects within time, budget, and quality specifications. The study recommends the need for appropriate mitigative measures against potential risks, such as delayed disbursement of funds by external financiers, delayed approval of contractors' payment requests, as well as community participation and involvement of civil society to influence accountability in the management of project funds and expedite disbursement of funds for subsequent project phases.
\end{abstract}

Keywords: infrastructural projects, contractor, delayed payment, budget overrun, time overrun

\section{Introduction}

Sondu-Miriu hydropower (SMHP) project is located in Kisumu County, about 337 kilometres from

\footnotetext{
* Acknowledgement: Special thanks go to the University of Nairobi for granting opportunity to the first author to pursue his Master of Arts Degree Project Planning and Management. Secondly, all the participants who took their time to provide the requisite information are thanked. Thirdly, the support provided by Tom Odhiambo in reviewing the manuscript is acknowledged.

Maurice Paul Okeyo, M.A., project planning and management, University of Nairobi, Nairobi, Kenya.

Charles Mallans Rambo, Ph.D., extra mural studies, University of Nairobi, Nairobi, Kenya.

Paul Amollo Odundo, Ph.D., education administration, University of Nairobi, Nairobi, Kenya.

Correspondence concerning this article should be addressed to Charles Mallans Rambo, P.O. Box 30197-00100, Nairobi, Kenya. E-mail: crambo@uonbi.ac.ke; rambocharls@gmail.com.
} 
Nairobi. The project is a run-of-the-river scheme, relying on the water from the Sondu-Miriu River, flowing into Lake Victoria. The project was initiated by Kenya Electricity Generating Company Limited (KenGen) to inject an additional 80 mega watts of electricity into the national grid and more particularly to support the economy of western Kenya, which had a power deficit of about 75 mega watts at the time the project was initiated in 1995 (KenGen, 2004).

The project was financed by the Government of Japan through Japanese International Corporation Agency (JICA), under Overseas Development Agency (ODA) loans at a cost of KES 18 billion (JICA, 1985). The loan was disbursed in two phases: in 1999, where KenGen received about $40 \%$ of the approved funds; in 2004, where the remaining $60 \%$ of the funds was disbursed. Phase I funding covered civil works and engineering services; while Phase II funding covered remaining civil works, hydro-mechanical works, generating equipment, and transmission line works (KenGen, 2004; Nippon Koei, 2008). According to the initial construction plan, the project was supposed to be completed by December 2005. However, due to delay, the project's completion date was revised to November 2011. Among the factors that contributed to the delay was delay in the payment of contractors for completed works (Nippon Koei, 2008; Abiero, 2010).

As noted by Alaghbari, Kadir, Salim, and Ernawati (2007), late and inconsistent payment of contractors for completed works is one of the critical factors, causing delays in the completion of infrastructural projects in developing countries. Delay in payment at the higher end of hierarchy is likely to trickle down the chain of contracts (Construction Industry Working Group on Payment, 2007). More specifically, delay in payment of completed works is likely to constrain contractors' cash flow, which in turn might affect timely payment of sub-contractors, workers, suppliers, and service providers. Regarding human labor, delayed payment of workers is likely to affect motivation, punctuality, productivity, honesty, pace of works, and completion of construction projects.

Memon, Rahman, Aziz, Ravish, and Hanas (2011) have associated prolonged delays in payment with consequences, such as high risk of industrial disputes, wanton destruction of property, and a high turn-over of workers; while Raj and Kothai (2014) pointed out that timely payment of workers is necessary for maintaining motivation, willingness, confidence, discipline, and cheerfulness to perform work. Furthermore, Abdul-Rahman, Takim, and Min (2009) linked delayed payment to causal factors, such as clients' poor financial and business management; financial impropriety and political interference; inaccurate valuation for completed works; as well as insufficient documentation and information for valuation, among other factors. Whereas causes of delays in the construction of infrastructural projects have attracted many studies, particularly in developing economies, the effects of such delays have not received as much attention (Sambasivan \& Soon, 2007; Aziz, 2013; Owolabi et al., 2014). More specifically, few studies, such as Sambasivan and Soon (2007), Abdul-Rahman et al. (2009), and Memon et al. (2011), have focused on the effects of delayed payment of contractors on the completion of infrastructural projects.

In Kenya, no studies have ever assessed the effect of delayed payment of contractors on the completion of infrastructural facilities. This study examined the effects of delayed payment of contractors on the completion of SMHP project by aggregating perspectives of the project's key stakeholders, including KenGen (the employer), Nippon Koei Company Limited (the engineer), Sinohydro (the contractor), and JICA (the financier). The study further applied a coefficient of concordance to determine the degree of agreement among the four categories of participants with respect to their ranking. The study addressed two research questions: What is the relative importance of delayed payment of contractors compared to other forms of contractual delays? What is 
the perceived effect of delayed payment of contractors on the project's completion?

The purpose of the study was to inform stakeholders about the potential negative effects of delayed payment of contractors on the completion of large infrastructural projects. The study also intended to contribute to existing literature on infrastructural project delays, particularly in Sub-Sahara African (SSA) countries, with a view to sensitizing stakeholders to work towards lessening such delays, in order to deliver inspirational, durable, efficient, and safe infrastructural facilities within scheduled timeframes and allocated budgets. Enhancing efficiency in the construction of infrastructural facilities is particularly important for SSA countries, where available resources cannot suffice the need for more infrastructural facilities and where nearly half of the population live on less than US\$1.25 a day (World Bank, 2015; Gutman, Sy, \& Chattopadhyay, 2015).

\section{Literature Review}

Infrastructural projects are considered successful when delivered within scheduled duration, allocated budget, and specified quality (Majid, 2006; Owolabi et al., 2014). Delay in the completion of infrastructural facilities is a critical challenge with a global dimension, often leading to increased construction costs due to time extension or acceleration as well as loss of productivity, disruption of work, loss of revenue through lawsuits between contractual parties, and project abandonment (Sambasivan \& Soon, 2007; Owolabi et al., 2014). Many SSA economies experience losses amounting to billions of dollars, as a result of delayed completion of infrastructural projects, which undermines the noble goal of poverty reduction (Gutman et al., 2015). Delay in the completion of infrastructural projects has significant cost implications, which in turn bears far-reaching consequences in the lives of citizens, especially in SSA countries. Costs arising due to such delays often manifest themselves in terms of accumulated interest on loans, high cost of maintaining management staff, as well as continuous escalation in wages and material prices.

Studies conducted in various contexts have deduced that although delay in the completion of infrastructural projects is a global phenomenon, it appears to be more common in developing than in developed countries (Sambasivan \& Soon, 2007; Alaghbari et al., 2007; Aziz, 2013). Among the developed countries, delay in the completion of infrastructural projects has been reported in Canada, the United States, Australia, and Britain, among others. In Canada for instance, De Souza (2009) attributed delays in the completion of infrastructural projects to various factors, including reduced funding by sponsors, communication breakdown, delayed disbursement of funds, poor site management by contractors, and tedious legislative procedures. In the United States, SNL Financial (2010) reported delay in the completion of a pipeline project connecting Florida State and Bahamas, particularly due to design changes; while Baldwin and Manthei (1971) associated project delays in the United States with weather vagaries, labor supply, and poor management of sub-contractors.

In developing countries, delays in the completion of infrastructural projects have been reported in India, Malaysia, Indonesia, Qatar, Jordan, Egypt, Ghana, South Africa, and Kenya, among other countries. In India, a government Infrastructure Delay Report of 2006 reported delays in the completion of a rail project in West Bengal and a coal project for about three and two decades, respectively, which were attributed to slow design processes and late disbursement of project funds (Government of India, 2006). In Qatar, a Public Works Report of 2009 linked delays in the completion of about one-third of infrastructural projects to contractors lack of capacity, escalation of construction material prices, prolonged transfer of land ownership rights to contractors, deferral of payments due to design issues, as well as legislative challenges in the procurement of necessary equipment and machinery from overseas market (Government of Qatar, 2009). 
In Malaysia, Sambasivan and Soon (2007) identified causes of delays in the completion of infrastructural projects, including contractor's improper planning, poor site management, inadequate experience, inconsistent flow of payments for completed work, poor management of sub-contractors, inconsistent communication between parties, as well as shortage of materials, equipment, and labor. In South Africa, a government report linked infrastructural project delays with changes in project design, inconsistent flow of financial resources, and contractor's lack of capacity to deliver (Government of South Africa, 1999). In Ghana, delay in payments, poor contractor management, delays in material procurement, poor technical performances, and escalation of material prices were identified as key factors accounting for about $80 \%$ of delays in the completion of infrastructural projects (Frimpong, Olowoye, \& Crawford, 2003).

In Kenya, delays in the completion of infrastructural facilities have been associated with factors, such as poor financial management by government agencies, inadequate designs, and poor management of the construction process by contractors (Talukhaba, 1999). Arguably, these factors are compounded by secondary factors, such as poor management of materials and equipment by contractors, inadequate recognition and response to risks emanating from the physical and socio-economic environments, as well as inadequate regard for stakeholders' needs (Talukhaba, 1999). Another study conducted by Ondari and Gekara (2013) reported significant correlation between project delays and factors, such as management support $(r=0.625)$, design specifications $(r=0.836)$, contractor's capacity $(r=0.567)$, and supervision capacity $(r=0.712)$.

Delays in the completion of infrastructural facilities were also identified by Abiero (2010) in the study that examined challenges of stakeholder management in implementation of SMHP project in Kenya. The study reported that the Phase II of the SMHP project delayed for four and half years due to delays in the release of funds, which in turn was caused by delay in the management of issues arising, including unsatisfactory accountability for funds released in the previous phase and improper management of dissenting voices among stakeholders (Abiero, 2010). The study further cited cases of delayed infrastructural projects in the lake region of Kenya, including the Kisii-Chemosite Road, which delayed for more than 15 years, as well as the Nyanza Provincial Headquarters, which stalled for more than two decades. The study noted that delayed completion of the projects has led to loss of both time and possession utility of the projects.

The literature review shows that most studies focused on causes of delays in the completion of infrastructural projects in developed and developing countries, with a few to explicitly identifying delayed payment of contractors, as one of the factors contributing to delayed completion of the cited projects. More still, no study has ever examined the effects of delayed payment of contractors on the completion of infrastructural projects.

\section{Methodology}

The study adopted a causal-comparative design, which permitted the application of quantitative approaches in data collection, processing, and analysis. Causal-comparative designs employ natural selection principle, rather than manipulation of dependent variables to reveal relationships with independent variables (Oso \& Onen, 2005). Self-administered questionnaires were issued to the management staff of contracting parties to source information on causes of contractual delays and effects of delayed payment of the contractor on the completion SMHP project. Primary data were supplemented with secondary data sourced from the project archives.

The study targeted senior management staff of SMHP project, affiliated to all contracting parties, including KenGen (the employer), Nippon Koei Company Limited (the engineer), Sinohydro (the contractor), 
and JICA (the financier). Senior management staff members were targeted, because contractual issues form part of their responsibility. A sampling frame of all senior management staff was prepared using organizational management charts of each contracting party and the process identified 54 eligible participants, who were all included in the sample to avoid the risk of sampling error (Table 1).

Table 1

Sampling Frame

\begin{tabular}{lcc}
\hline Contracting partner type & Frequency & Percent \\
\hline Employer & 15 & 27.8 \\
Contractor & 20 & 37.0 \\
Engineer & 15 & 27.8 \\
Financier & 4 & 7.4 \\
Total & 54 & 100.0 \\
\hline
\end{tabular}

Self-administered questionnaires were used to source the information, particularly because they provided the flexibility that targeted participants would require, considering their complicated itineraries. The approach enabled participants to provide the requisite data at their convenience. One module of the instrument was applied across the board to permit comparison of perspectives from different contracting parties. The instrument, which had both closed- and open-ended questions, captured information on contractual delay typology, perceived causes and effects, as well as mitigative measures.

The instrument was pre-tested at the Kisumu Airport Expansion Project, which had a similar contractual management structure. The pre-testing was important for testing reliability of the instrument, validity, and feasibility of data collection approaches. Primary data were collected in May 2011 after obtaining necessary approval from University of Nairobi, National Council of Science and Technology, as well as KenGen. Questionnaires were delivered to targeted participants and follow-ups were made through e-mails and telephone calls. Of the 54 targeted participants, 39 (72\%) successfully completed and returned the questionnaires. Table 2 shows the questionnaire return rate for each category of participants.

Table 2

Questionnaire Return Rate

\begin{tabular}{llll}
\hline Contracting partner type & No. targeted & No. of participants & Return rate $(\%)$ \\
\hline Employer & 15 & 14 & 93.3 \\
Contractor & 20 & 12 & 60.0 \\
Engineer & 15 & 10 & 66.7 \\
Financier & 4 & 3 & 75.0 \\
Total & 54 & 39 & 72.2 \\
\hline
\end{tabular}

Primary data were listed, coded, digitalized, and cleaned for logical inconsistencies and misplaced codes. The methods used included descriptive, factorial comparative, and rank analyses, to develop relative importance of causes and effects of contractual delay on the project's completion. Relative importance index (RII) was computed using the formula (Kometa, Oloimolaiye, \& Harris, 1994).

$$
\mathrm{RII}=\frac{\Sigma W}{A \times N}
$$


where $W$ is the weighting assigned to each response on a scale of 1 to 5 corresponding with lowest to highest; $A$ is the highest weight; and $N$ is the total number of participants.

RII yielded values in the range of $0<x \geq 1$. The higher the value of RII is, the more important the identified factor on contractual delays is. This ranking enabled cross comparison of the relative importance of the factors as perceived by the four categories of participants. RII is a non-probabilistic rank statistic derived from ordinal data; hence, its accuracy is non-dependent on sample size or the population.

Furthermore, Kendell's coefficient of concordance was applied to determine the degree of agreement among the four categories of participants with respect to their ranking (Frimpong et al., 2003). The coefficient states that the degree of agreement on a 0 to 1 scale is given by $W$, such that:

$$
W=\frac{12 U-3 m^{2} n(n-1)^{2}}{m^{2} n(n-1)}
$$

where,

$$
U=\sum_{j=1 \ldots n}\left(\sum R\right)^{2}
$$

where $n$ is the number of factors; $m$ is the number of groups; and $j$ represent the factors $1,2,3, \ldots n$.

As noted by Frimpong et al. (2003), Kendell's coefficient of concordance is strong on both probabilistic and non-probabilistic distributions, because it is not sensitive to sampling error. In addition, Chi-square statistic was used to determine whether there was a significant difference in the ranking of contractual delay factors perceived to be influencing delays in the project's completion. The Statistical Package for Social Sciences (SPSS) and Microsoft Excel were used to analyze the data.

\section{Results}

The results of this study were organized, interpreted, and discussed under five thematic areas, including participants' profile, forms of contractual delay, components of contractual delay, and effects of delayed payment of the contractor on the project's completion. Details are presented and discussed under the following sub-sections.

\section{Participants' Professional and Work Experience}

The study covered 39 senior management staff of the contractual parties, including 14 (35.9\%) from KenGen, 12 (30.8\%) from Sinohydro, 10 (25.6\%) from Nippon Koei, and 3 (7.7\%) from JICA. The duration of professional and work experience is an important factor in successful management and administration of construction projects. In view of this, participants were requested to indicate the duration of experience in managing construction projects and more specifically, the duration of experience in managing SMHP project. The results are summarized in Table 3 .

The results show that the employer's staff reported an average professional experience of 2.6 years in the management of construction projects and 2.3 years in the management of SMHP project. The contractor's staff indicated an averaged experience of 2.1 years and 1.7 years in the management of construction projects and SMHP project, respectively. Engineer's staff reported an average experience of 3.0 and 2.1 years; while the Financier's staff stated the least experience of 2 years in the management of construction projects and 1.3 years in SMHP project.

The results suggest low variability of experience among participants. The average experience was 2.4 years in management of construction projects and 1.9 years in management of the project. The engineer's staffs were the most experienced with a relative weight of 1.0 compared to the employer's 0.9 and the contractor's 
0.7. The least relative management experience was noted among the financier's staff, which was weighted at 0.6. Low variability further suggests that the participants were fairly homogenous in terms of professional experience and therefore provided reliable information with negligible internal deviation of \pm 0.03 year.

Furthermore, the contractual documents revealed that the employer set a minimum professional experience in managing construction projects at three years, upon which the reported duration of professional experiences was compared. The results show that only the engineer's staff met the minimum threshold, which may suggest that the employer might have failed to exercise authority to ensure adherence to the standard by all contractual parties. Projects which are managed by highly experienced personnel have a relatively lower risk of experiencing contractual delays, due to the management's ability to proactively assess and mitigate potential risk factors. In view of this, the staff of most contractual parties reported a professional experience, which is lower than the threshold set in the contractual documents, which might have contributed to the contractual delay experienced in SMHP project.

Participants were requested to indicate their perspectives on whether SMHP project was on time or in delay. The results presented in Table 4 show that out of the 14 staff of the employer, 11 (78.6\%) indicated that the project was in delay. The same status was confirmed by all the staff members of the contractor (12), the engineer (10), and the financier (3).

Table 3

Professional and Work Experience

\begin{tabular}{lllll}
\hline \multirow{2}{*}{ Contractual party } & Frequency & \multicolumn{2}{c}{ Average experience (years) } & Relative weighted \\
\cline { 3 - 5 } management
\end{tabular}

Table 4

Perception on the Timeliness of the Project

\begin{tabular}{llccc}
\hline \multirow{2}{*}{ Contractual partner type } & \multicolumn{2}{c}{ Yes } & No \\
\cline { 2 - 5 } & Frequency & Percent & Frequency & Percent \\
\hline Employer & 3 & 21.4 & 11 & 78.6 \\
Contractor & 0 & 0.0 & 12 & 100.0 \\
Engineer & 0 & 0.0 & 10 & 100.0 \\
Financier & 0 & 0.0 & 3 & 100.0 \\
Total & 3 & 7.7 & 36 & 92.3 \\
\hline
\end{tabular}

Overall, $36(92.3 \%)$ participants across the contractual parties affirmed that the project was not on schedule, while $3(7.7 \%)$ expressed contrary opinions, suggesting that some participants might not be having sufficient experience in the project's delay aspects. Nonetheless, the high proportion of participants (92.3\%), affirming that the project was in delay, is a robust indication that the project's completion was behind schedule.

\section{Forms of Delay in SMHP Project}

Three main forms of project delay, namely, contractual, stakeholder, and force majeure, were listed in 
the data collection instrument and participants requested to indicate their opinion regarding the frequency of occurrence on a five-point integer scale ranging from 1 to 5 and corresponding to "very low", "low", "medium", "high", and "very high". A mean statistic, indicating convergence among groups, was computed to establish agreement among participants on the frequency of occurrence. Table 5 provides a summary of the findings.

Table 5

Forms of Delay on SMHP Project

\begin{tabular}{lllllll}
\hline \multirow{2}{*}{ Contractual partner type } & \multicolumn{2}{c}{ Contractual delay } & \multicolumn{2}{c}{ Stakeholder delay } & \multicolumn{2}{c}{ Force majeure } \\
\cline { 2 - 7 } & Mean & Category & Mean & Category & Mean & Category \\
\hline Employer & 3.8 & High & 3.8 & High & 1.8 & Low \\
Contractor & 2.8 & Medium & 2.3 & Low & 2.9 & Medium \\
Engineer & 3.8 & High & 1.5 & Low & 1.5 & Low \\
Financier & 3.7 & High & 2.1 & Low & 1.7 & Low \\
Convergence & 3.5 & High & 2.4 & Low & 2.0 & Low \\
\hline
\end{tabular}

The results show that the most common form of delay was contractual, scoring an average of 3.8 (high) among the employer's staff, 2.8 (medium) among the contractor's staff, 3.8 (high) among the engineer's staff, and 3.7 (high) among the financier's staff. Overall, the analysis obtained a convergence of 3.5 (high) across all the groups. Regarding the stakeholder form of delay, the analysis obtained a mean score of 3.8 (high) among members of the employer's group, 2.3 (low) among members of the contractor, 1.5 (low) among members of the engineer, and 2.1 (low) among employees of the financier. The overall convergence was 2.4 (low) across all the groups, which is an indication that the frequency of stakeholder delay was lower than contractual delay.

The results in Table 5 further show that force majeure was the least common form of delay with scores of 1.8 (low) for the employer, 2.9 (medium) for the contractor, 1.5 (low) for the engineer, 1.7 (low) for the financier, and a convergence of 2.0 (low) across all the groups. This also implies that the frequency of force majeure was the least common form of delay in the context of SMHP project. The results indicated the relative importance and hence, agreement among contractual parties regarding the order of importance.

\section{Components of Contractual Delay: Payment of Contractors}

Contractual delay is a manifestation of failure by contractual parties involved to perform their obligations under the contract. Such obligations may include timely payment of workers for accomplished construction works as well as timely mobilization of necessary equipment or machinery and manpower, among others. In view of this, the study sought to establish perceptions of the management staff regarding the occurrence of payment and resource mobilization delays in the context of SMHP project. In this regard, participants were requested to state at a nominal scale of "yes" or "no", whether payment of the contractor ever occurred during the project's implementation, the results of which are presented in Table 6.

The study found that delay in payment of the contractor for completed works was experienced during the project's construction. Overall, about one-half $(49.9 \%)$ of the participants across all groups affirmed that the project experienced delays in payment of the contractor for completed works. The analysis obtained RII for each form of contractual delay to facilitate ranking in terms of seriousness. The results show that delay in payment of the contractor might have been fairly serious, with an RII of 0.5 . 
Table 6

Components of Contractual Delay (\%)

\begin{tabular}{|c|c|c|c|c|c|c|c|c|c|c|c|}
\hline \multirow{2}{*}{ Components of delay } & \multicolumn{2}{|c|}{ Employer } & \multicolumn{2}{|c|}{ Engineer } & \multicolumn{2}{|c|}{ Contractor } & \multicolumn{2}{|c|}{ Financier } & \multicolumn{2}{|c|}{ Overall } & \multirow{2}{*}{ - RII } \\
\hline & Yes & No & Yes & No & Yes & No & Yes & No & Yes & No & \\
\hline Design & 57.2 & 42.8 & 79.9 & 20.1 & 92.3 & 7.7 & 100.0 & 0.0 & 82.4 & 17.6 & 0.8 \\
\hline Payment & 42.8 & 57.2 & 40.0 & 60.0 & 49.7 & 50.3 & 67.0 & 33.0 & 49.9 & 50.1 & 0.5 \\
\hline Site possession & 56.7 & 43.3 & 9.8 & 90.2 & 58.0 & 42.0 & 0.6 & 99.4 & 31.3 & 68.7 & 0.3 \\
\hline Mobilization & 50.3 & 49.7 & 90.2 & 9.8 & 33.3 & 66.7 & 99.6 & 0.4 & 68.4 & 31.6 & 0.6 \\
\hline Legal procedures & 42.5 & 57.5 & 80.4 & 19.6 & 66.8 & 33.2 & 67.4 & 32.6 & 64.3 & 35.7 & 0.5 \\
\hline
\end{tabular}

\section{Effects of Delayed Payment of the Contractor on the Project's Completion}

Contractual documents reveal that payment of the contractor for completed works was the employer's responsibility. The contractor was required to submit payment requests, supported with the engineer's certification, in accordance with contracted schedule. The employer was obligated to honor payment requests within the time specified in the contract. However, the results show that about one-half $(49.9 \%)$ of the participants identified delayed payment of the contractor for completed works as one of the factors that may contribute to delay in the project's completion. Participants attributed delayed payments to late disbursement of funds by the financier and the employer's inefficient financial management system. Regarding the perceived effects of delay in payment on the completion of SMHP project, Table 7 presents the results.

Table 7

Effects of Payment Delay on the Project's Completion (\%)

\begin{tabular}{lllrrrrrrrrr}
\hline \multirow{2}{*}{ Effect } & \multicolumn{3}{c}{ Employer } & \multicolumn{3}{c}{ Contractor } & \multicolumn{3}{c}{ Engineer } & \multicolumn{3}{c}{ Financier } & \multicolumn{3}{c}{ Total } \\
\cline { 2 - 12 } & Yes & No & Yes & No & Yes & No & Yes & No & Yes & No \\
\hline Prevents early completion & 57.1 & 42.9 & 83.3 & 16.7 & 20.0 & 80.0 & 33.3 & 66.7 & 53.8 & 46.2 \\
Extends time \& acceleration & 71.4 & 28.6 & 100.0 & 0.0 & 30.0 & 70.0 & 66.7 & 33.3 & 69.2 & 30.8 \\
Loss of productivity \& efficiency & 64.3 & 35.7 & 100.0 & 0.0 & 50.0 & 50.0 & 66.7 & 33.3 & 71.8 & 28.2 \\
Re-scheduling \& re-sequencing & 71.4 & 28.6 & 91.7 & 8.3 & 40.0 & 60.0 & 66.7 & 33.3 & 69.2 & 30.8 \\
Increase time-related costs & 78.6 & 21.4 & 100.0 & 0.0 & 40.0 & 60.0 & 33.3 & 66.7 & 71.8 & 28.2 \\
Abandonment of project & 35.7 & 64.3 & 16.7 & 83.3 & 10.0 & 90.0 & 0.0 & 100.0 & 20.5 & 79.5 \\
$n$ & 14 & & 12 & & 10 & & 3 & & 39 & \\
\hline
\end{tabular}

The results show that delay in payment of the contractor for completed works affected the project by causing: loss of productivity and efficiency $(71.8 \%)$, increase in time-related costs $(71.8 \%)$, re-scheduling and re-sequencing of works $(69.2 \%)$, extension of time and acceleration $(69.2 \%)$, as well as prevention of early completion (53.8\%). Timely payment for completed works is a key factor determining the level of productivity and efficient utilization of resources, including time, towards project's completion. Participants indicated that delay in payment caused anxiety among workers, leading to low motivation, sub-optimal productivity, labor unrest, and periodical discontinuation of works. The negative consequences of delay in payment and extended periods of cash shortage intertwined to prevent timely implementation of work plans and completion of the project.

Participants further associated delay in payment with slow progression of works and inefficient utilization of time, which in turn, had negative implications on time-related costs, such as maintenance of management 
staff, renting equipment, paying insurance premiums, servicing interest on loans, and paying for security services, among others. Participants further noted that periodical discontinuation of works and labor unrests dragged the implementation of work plans, which necessitated re-scheduling and re-sequencing of project activities, albeit with cost implications. Participants noted that re-scheduling and re-sequencing of project activities are expensive and complicated planning processes, requiring the participation of all stakeholders.

Participants also linked delay in payment with the extension of timeframe and acceleration of works, which was intended to make up for lost time. Acceleration of works, including overtime, shifts, out-of-sequence work, as well as bloating workforce, was associated with reduced labor productivity and inefficiency, with heavier financial implications on the project's budget. More still, participants observed that acceleration of works heightened the risk of construction works not meeting quality standards, which may affect durability, operational efficiency, profitability, and safety of the infrastructural facilities. In their study, G. Sweis, R. Sweis, Abu-Hammad, and Shboul (2008) agreed that delay in payment was the most frequent cause of project completion delay resulting to inefficiency and extension of time frame and acceleration of works. In view of this, delay in payment of contractors is a costly challenge that requires effective financial management systems on the part of the employers and proper cash flow management on the part of contractors.

\section{Discussions}

The aim of this study was to determine effects of delayed payment of the contractor on the completion of SMHP project. The study relied on the perspectives of senior managerial staff of the contractual parties, including KenGen (the employer), Nippon Koei Company Limited (the engineer), Sinohydro (the contractor), and JICA (the financier). The purpose was to sensitize stakeholders about the negative effects of delayed payment of contractors on the timely completion of infrastructural projects as well as contribute to existing literature on infrastructural project delays, particularly in SSA countries, with a view to sensitizing stakeholders to work towards lessening such delays in order to save resources for other development activities.

The results of this study showed that delay in payment of the contractor for completed works affected the project by causing: loss of productivity and efficiency (71.8\%); increase in time-related costs (71.8\%); re-scheduling and re-sequencing of works (69.2\%); extension of time and acceleration $(69.2 \%)$; as well as prevention of early completion (53.8\%). Even though stakeholders coped with the effects of delayed payment of the contractor by re-scheduling and re-sequencing of project activities as well as extending timeframe and accelerating works, there was no evidence linking such measures with timely completion of the project.

Instead, participants amplified the heavy budgetary implications of the processes, which might have exhausted contingency funds. Hence, delayed payment of contractors is one of the factors likely to cause budget overruns, which in turn may stall infrastructural projects for a long time, thus, delaying the contribution of such facilities to national social and economic development.

Efficient management of infrastructural projects is particularly important in resource-poor contexts, such as the SSA region. A high level of efficiency is preferable and likely to save resources that can be invested in the construction of more infrastructural facilities. Timely payment of contractors for completed works is one way through which SSA countries can ensure efficiency in the management of infrastructural projects. There is no doubt that delay in payment is likely to raise anxiety, reduce productivity, retard progression of works, and instigate labor unrests; which may affect the environment required for timely completion of infrastructural projects. Project delays and subsequent wastage of resources may be considered unfavorable for SSA 
economies, where about one-half of the population (47\%) live in extreme poverty. Investing in infrastructural facilities should help reduce rather than exacerbate poverty levels.

\section{Conclusions}

Timely payment of contractors for completed works is crucial for ensuring the continuity of works and completion of infrastructural projects within time, budget, and quality specifications. Payment of contractors is likely to prevent cost and time overruns, which may have significant ripples effect, particularly in low-income economies, such as SSA countries. In view of this, payment of contractors should be planned properly by initiating appropriate mitigative measures against potential risks, such as delayed disbursement of funds by external financiers, delayed approval of contractors' payment requests, political interference, as well as financial misappropriation by employers, among others. Mitigating such risks, however, requires the involvement of stakeholders at the national, project, and community levels. Community participation and involvement of civil society are particularly crucial for influencing leaders to expedite budget approval and fund disbursement processes.

At the project level, community participation should be encouraged to enhance accountability in handling and managing project funds by accounting officers. Efficiency of financial management system at the project level should be reflected by prompt filing of returns to relevant authorities to facilitate timely release of funds for subsequent project phases. Good project managers should understand that cash flow is the lifeblood of infrastructural projects, without which delay, abandonment, and subsequent wastage of resources become inevitable.

\section{References}

Abdul-Rahman, H., Takim, R., \& Min, W. S. (2009). Financial-related causes contributing to project delays. Journal of Retail and Leisure Property, 8, 225-238.

Abiero, A. (2010). Challenges of stakeholder management in implementation of Sondu Miriu hydropower project in Kenya (Master's thesis in business administration, University of Nairobi).

Alaghbari, W. E., Kadir, M. R. A., Salim, A., \& Ernawati, K. (2007). The significant factors causing delay of building construction projects in Malaysia. Engineering, Construction and Architectural Management, 14(2), 192-206.

Aziz, R. F. (2013). Factors causing cost variation for constructing wastewater projects in Egypt. Alexandria Engineering Journal, 52, 51-66.

Baldwin, J., \& Manthei, J. (1971). Delay causes in the construction industry. Journal of the Construction Division, 97(2), 177-187.

Construction Industry Working Group on Payment. (2007). The importance of payment in the construction industry (Report on Enactment of Construction Industry Payment and Adjudication Act (CIPAA)).

De Souza, M. (2009). Project delays. Post Medium News, p. 43.

Frimpong, Y., Olowoye, J., \& Crawford, L. (2003). Causes of delay and cost overruns in construction of ground water projects in developing countries: Ghana as a case study. International Journal of Management, 21(1), 321-326.

Government of India. (2006). Infrastructure delay report. New Delhi: Ministry of Statistics.

Government of Qatar. (2009). Major project and infrastructure in Qatar. Doha: Ministry of Public Works.

Government of South Africa. (1999). Design and construction of infrastructure projects. Cape Town: Department of Public Works.

Gutman, J., Sy, A., \& Chattopadhyay, S. (2015). Financing African infrastructure: Can the world deliver? Washington, DC: Global Economy and Development at Brookings.

Japanese International Cooperation Agency. (1985). Feasibility study for Sondu River Basin. Nairobi: JICA.

KenGen. (2004). Sondu-Miriu hydroelectric power project (Unpublished project briefing paper for the Parliamentary Committee on energy). 
Kometa, S. T., Oloimolaiye, P. O., \& Harris, F. C. (1994). Attributes of UK construction clients influencing project consultants' performance. Construction Management Economics, 12, 433-443.

Majid, I. (2006). Causes and effect of delays in Aceh construction industry (Master's thesis, University Technology, Malaysia).

Memon, A. H., Rahman, I. A., Aziz, A. A. A., Ravish, K. V., \& Hanas, N. I. M. (2011). Identifying construction resource factors affecting construction cost: Case of Johor. Proceedings from Globalizing Innovation for Sustainable Transformation, Batu Pahat, Johor, Malaysia.

Nippon Koei. (2008). Delay to Sondu-Miriu hydropower report (Unpublished project report, Nairobi, Kenya).

Ondari, P. O., \& Gekara, J. M. (2013). Factors influencing successful completion of roads projects in Kenya. International Journal of Arts and Entrepreneurship, 1(5), 1-22.

Oso, W. Y., \& Onen, D. (2005). General guide to writing research proposal and report: A handbook for beginning researchers. Kisumu, Kenya: Options Printers and Publishers.

Owolabi, J. D., Amusan, L. M., Oloke, C. O., Olusanya, O., Tunji-Olayeni, P., Owolabi, D., ... Omuh, I. (2014). Causes and effect of delay on project construction delivery time. International Journal of Education and Research, 2(4), 197-208.

Raj, B. V. A., \& Kothai, P. S. (2014). Improving the labour productivity through other resources in construction field. International Journal of Engineering Research and General Science, 2(2), 205-213.

Sambasivan, M., \& Soon, Y. (2007). Causes and effects of delays in Malaysian construction industry. International Journal of Project Management, 25, 517-526.

SNL Financial. (2010). Sector focus intelligence. London: SNL Press.

Sweis, G., Sweis, R., Abu-Hammad, A., \& Shboul, A. (2008). Delays in construction projects: The case of Jordan. International Journal of Project Management, 26, 665-674.

Talukhaba, A. A. (1999). An investigation into factors causing construction project delays in Kenya (A Ph.D. thesis, Department of Building Economics and Management, University of Nairobi).

World Bank. (2015). Global monitoring report 2014/2015: Ending poverty and sharing prosperity. Washington, DC: IBRD/World Bank. 